\title{
Zonal Disintegration Effect of Deep Straight Wall Semicircular Arch with Different Roadway Heights
}

\author{
Jiao Zhang*, Huifang Li \\ Dept. of School of Civil Engineering, Henan Polytechnic University, Jiaozuo, China \\ Email: *lavenderzj@163.com
}

How to cite this paper: Zhang, J. and $\mathrm{Li}$, H.F. (2020) Zonal Disintegration Effect of Deep Straight Wall Semicircular Arch with Different Roadway Heights. Open Access Library Journal, 7: e6749.

https://doi.org/10.4236/oalib.1106749

Received: August 26, 2020

Accepted: October 27, 2020

Published: October 30, 2020

Copyright $\odot 2020$ by author(s) and Open Access Library Inc.

This work is licensed under the Creative Commons Attribution International License (CC BY 4.0).

http://creativecommons.org/licenses/by/4.0/

\begin{abstract}
In order to study the zonal disintegration effect of deep straight wall semicircular arch roadway with different roadway heights, FLAC ${ }^{3 \mathrm{D}}$ numerical simulation software was used to systematically study the characteristics of plastic zone, surrounding rock deformation and surrounding rock abutment pressure distribution. The results show that: the rupture zone at the floor of straight wall semicircular arch roadway develops layer by layer in the form of " $X$ " and the displacement isoline at the roof is "eggshell shape". No matter what the value of roadway height is, a rectangular fracture zone will be formed; the surrounding rock deformation in $\mathrm{Z}$ direction of straight wall semicircular arch roadway exists in the form of "inverted triangle" at the floor, and the height of "inverted triangle" is constant no matter what the height of roadway is, that is, the area is certain; after the excavation of the roadway, the stress concentration phenomenon occurs on the left and right sides of the straight wall semicircular arch roadway; the phenomenon mostly occurs on both sides of the arch.
\end{abstract}

\section{Subject Areas \\ Geotechnical Engineering}

\section{Keywords}

Zonal Disintegration, Straight Wall Semicircular Arch, Roadway Height,

Plastic Zone, Abutment Pressure

\section{Introduction}

Coal, as a consumable, is non-renewable. The coal in the shallow part has been mined out by the impact of China's vigorous economic development in the last 
century, forcing people to turn their attention to the deep part. The deep part is affected by high ground stress, high osmotic pressure and high ground temperature. The stress characteristics of surrounding rocks are obviously different from those of shallow ones.

In the 1970s and 1980s, foreign scholars discovered the phenomenon of partition rupture. Adams and Jager (1980) [1] observed the fracture interval distribution at the roof of Witwatersrand gold mine in South Africa. Shemyakin et al. (1986) [2] discovered the zonal disintegration phenomenon in the Taimyrskii mine by using the resistivity meter, and further verified the existence of the phenomenon in the field. He (1991) [3] measured the ultrasonic velocity of the surrounding rock of the roadway in Zhuxianzhuang mine, Huaibei, in the form of "trough-peak-trough" interval distribution.

Russian scholar Odintsev (1994) [4] proposed the formation mechanism of zonal fracture based on the experimental data of deep rock mass, which can be used to describe and predict the periodic fracture of surrounding rock of underground cavern. Based on the energy method, Reva (2002) [5] proposed a failure criterion for brittle rock, which can consider different disturbance degree, and based on the failure criterion, proposed a method which can evaluate the stability of underground engineering with zone fracture. Based on the theory of unbalanced thermodynamics, Guzev and Paroshin (2001) [6] put forward a non-Euclidean continuous model and used it to analyze the stress field distribution of circular underground caverns.

Qiangyong Zhang et al. (2013) made use of model similar materials and numerical control true three-dimensional loading model test system, and got the conclusion that no matter the tunnel shape is horseshoe tunnel, circular tunnel or Chengmen tunnel, the fracture shape of surrounding rock zone is independent of the tunnel shape, and the shape of the outermost boundary of the zone fracture is approximate circle; when the initial maximum principal stress is greater than 1.5 times of the compressive strength of surrounding rock and parallel to the tunnel axis, the zone fracture occurs. The radial displacement and strain of the fractured surrounding rock in the area show alternating tension and pressure distribution of wave crest and wave trough, indicating that the failure area of the surrounding rock is at the wave crest with larger radial strain, and the non failure area of the surrounding rock is at the wave trough with relatively smaller radial strain (see Figure 1).

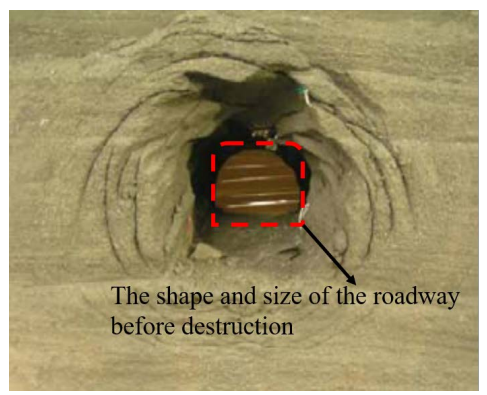

Figure 1. Zone disintegration of model test working condition 1. 
Based on the free energy density, equilibrium equation and non-conforming deformation condition, a new non-Euclidean model is proposed in the literature. The stress field of the surrounding rock of the deep circular roadway is obtained. When the density and half length of the microcracks in the surrounding rock are large, the vibration characteristics of the stress field of the surrounding rock are obvious. The microcracks in the stress wave peak area will expand and eventually form the fracture area, but in the stress wave valley area the microcracks will not propagate and eventually form non-ruptured area. The phenomenon of alternating peak and valley of surrounding rock stress field results in the alternating occurrence of fracture zone and non-ruptured area, that is, the phenomenon of zonal fracture (Qian et al., 2012 [7]; Qian and Zhou, 2011 [8]).

Since the discovery of zonal disintegration phenomenon, many scholars at home and abroad have expounded the mechanism and influencing factors of zonal disintegration from four aspects: zonal disintegration theory and mechanism, zonal disintegration similar experiment, zonal disintegration numerical simulation and field measurement. It is instructive for the support of deep roadways through the study of the phenomenon of zoning disintegration.

\section{Numerical Model}

\subsection{Basic Parameters of the Model}

At present, with the continuous improvement of excavation technology and equipment, the roadway section size also changes. In order to make the simulation study can reflect the zonal disintegration under the limit condition, the fixed roadway width is $5 \mathrm{~m}$, the section height is $1 \mathrm{~m}-8 \mathrm{~m}$, and the numerical model is established, as shown in Figure 2, the model length is $40 \mathrm{~m}$, the width is $2 \mathrm{~m}$, the height is $40 \mathrm{~m}$, the buried depth is $1000 \mathrm{~m}$, and the average density is $2500 \mathrm{~kg} / \mathrm{m}^{3}$. Different coal seam roof and floor strata are different. In order to simplify the simulation, combined with the characteristics of rock strain softening, the SS model is selected, and the simulation parameters are the general rock mechanical parameters of coal bearing strata, as shown in Table 1.

The row spacing of bolt support in coal mine is mostly between $0.6 \mathrm{~m}-1 \mathrm{~m}$, and the most common is $0.8 \mathrm{~m}$. The length of anchor bolt is mostly between 1.6 $\mathrm{m}$ and $2.5 \mathrm{~m}$, and the length of very few $3 \mathrm{M}$ is taken as $2.5 \mathrm{~m}$; the diameter of anchor bolt is between $16 \mathrm{~mm}$ and $22 \mathrm{~m}$, which is $22 \mathrm{~mm}$ in this simulation; the diameter of seven strand steel strand anchor cable is $15.24 \mathrm{~mm}-21.6 \mathrm{~mm}$, which is $21.6 \mathrm{~mm}$ in this simulation and $8.3 \mathrm{~m}$ in length. See Table 2 for specific numerical model excavation and support parameters.

\subsection{Simulation Scheme}

The buried depth of the fixed straight wall semicircle arch is $1000 \mathrm{~m}$, the roadway width is $5 \mathrm{~m}$, and the roadway height is $1-8 \mathrm{~m}$. The specific simulation scheme is shown in Table 3.

Simulation sequence: the model is initially set to the original rock stress state, and then excavation and support, that is, loading first and then excavation. 


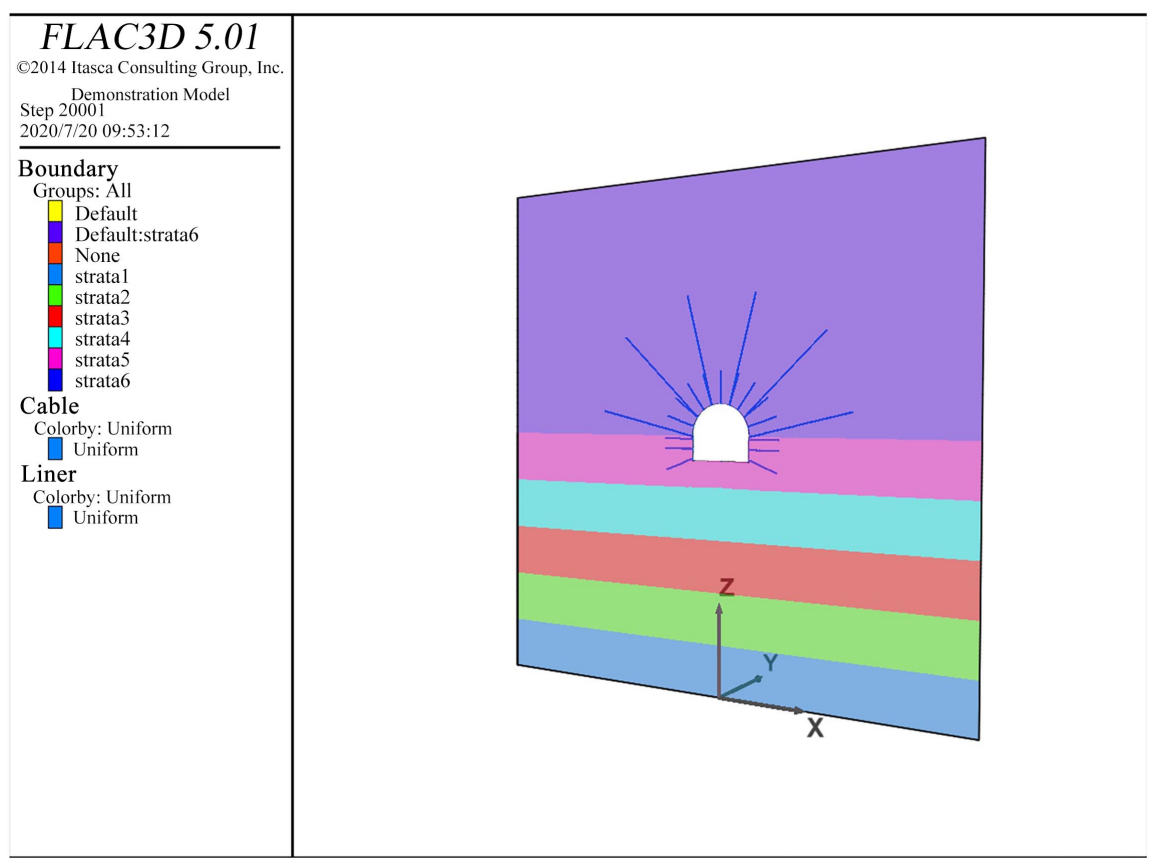

Figure 2. Numerical model.

Table 1. Mechanical parameters of model.

\begin{tabular}{cccccc}
\hline $\begin{array}{c}\text { Elastic } \\
\text { modulus }(\mathrm{GPa})\end{array}$ & $\begin{array}{c}\text { Poisson } \\
\text { ratio }(\mu)\end{array}$ & $\begin{array}{c}\text { Internal friction } \\
\text { angle }\left(^{\circ}\right)\end{array}$ & $\begin{array}{c}\text { Cohesion } \\
(\mathrm{MPa})\end{array}$ & $\begin{array}{c}\text { Tensile } \\
\text { strength }(\mathrm{MPa})\end{array}$ & $\begin{array}{c}\text { Dilatancy } \\
\text { angle }\left({ }^{\circ}\right)\end{array}$ \\
\hline 8 & 0.25 & 35 & 3 & 2 & 2 \\
\hline
\end{tabular}

Table 2. Parameters of numerical model excavation and support.

\begin{tabular}{cc}
\hline Anchor & Anchor cable \\
\hline Row spacing: $800 \times 800 \mathrm{~mm}$, & Row spacing: $1600 \times 800 \mathrm{~mm}$, \\
$\varphi 20 \times 2500 \mathrm{~m}$, lengthened anchorage & $\varphi 21.6 \times 830 \mathrm{~m}$, lengthened anchorage \\
\hline
\end{tabular}

Table 3. Simulation schemes of different roadway heights.

\begin{tabular}{ccccccccccc}
\hline \multicolumn{11}{c}{ Buried depth $1000 \mathrm{~m}$} \\
\hline roadway height & 1 & 2 & 3 & 4 & 5 & 6 & 7 & 8 \\
\hline
\end{tabular}

\section{Distribution Characteristics of Plastic Zone}

In Figure 3, the rupture zone at the floor of the straight wall semicircular arch roadway develops layer by layer in the form of " $Y$ " and there is an obvious phenomenon that the fractured zone and the non fractured zone exist alternately. With the increase of roadway height, the range of displacement isoline No.0 gradually shrinks and approaches, the number of displacement isolines increases, and the influence range of rupture zone is also increasing. The displacement isoline at roof is "eggshell". There is a similar rupture zone from Figures $3(\mathrm{a})-(\mathrm{h})$, that is, a rupture zone is led out from the intersection of arch wall and arch at $45^{\circ}$, which crosses with the fracture zone formed at the bottom of arch wall to form a closed rectangular fracture ring. 


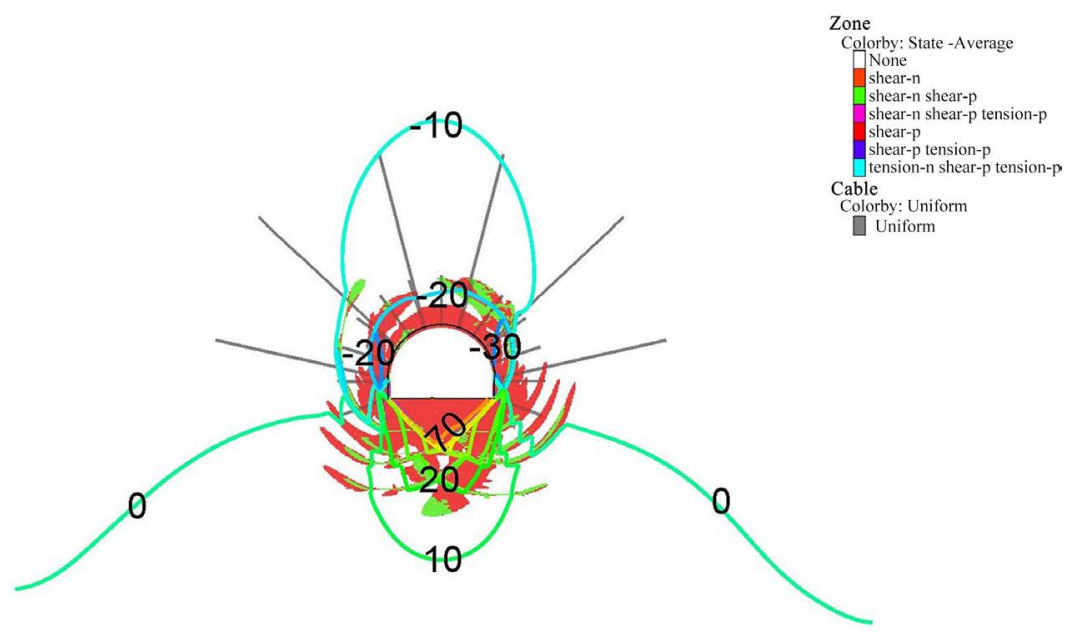

(a) $1 \mathrm{~m}$

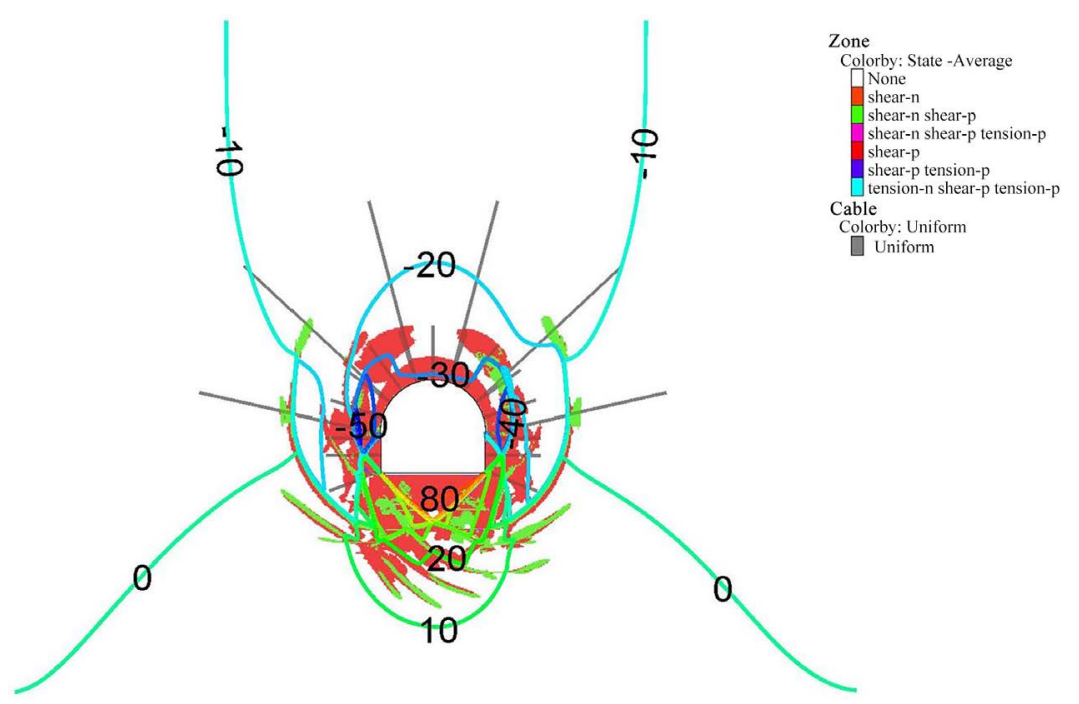

(b) $2 \mathrm{~m}$

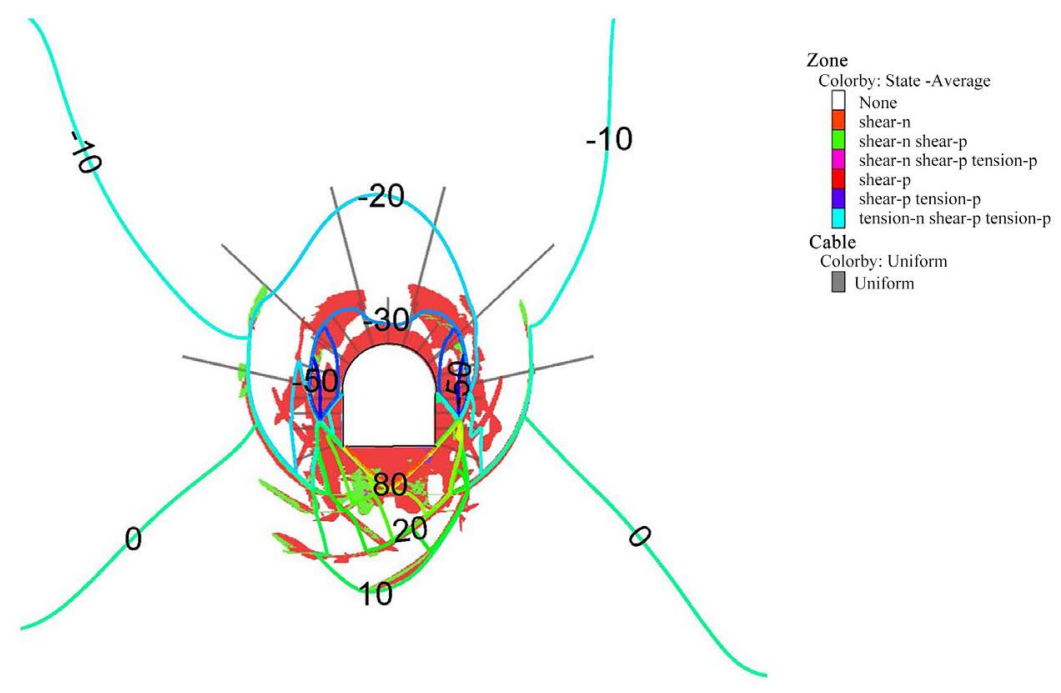

(c) $3 \mathrm{~m}$ 

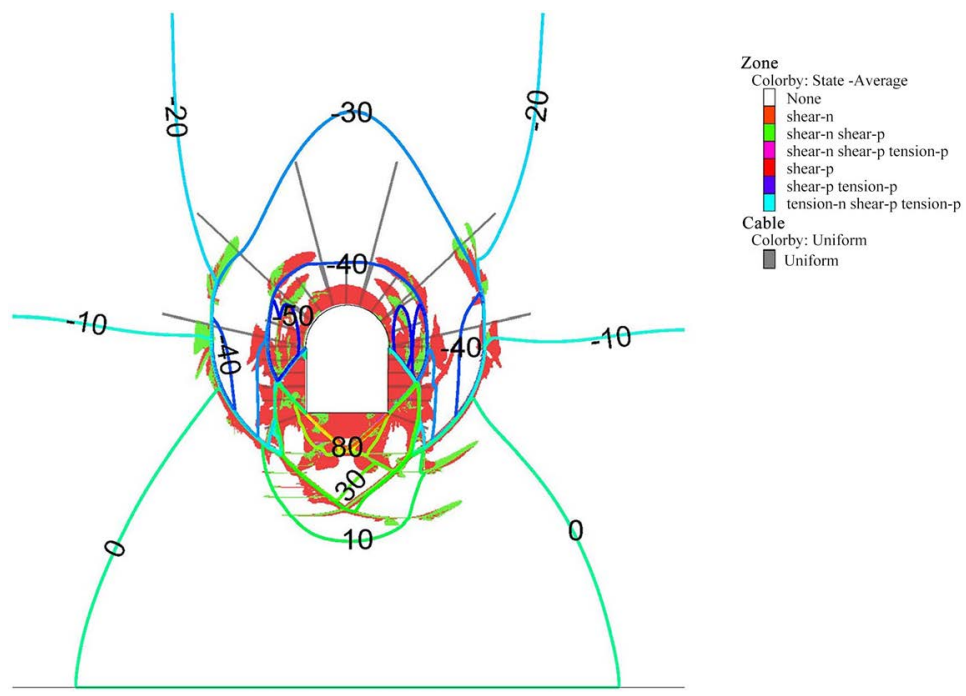

(d) $4 \mathrm{~m}$

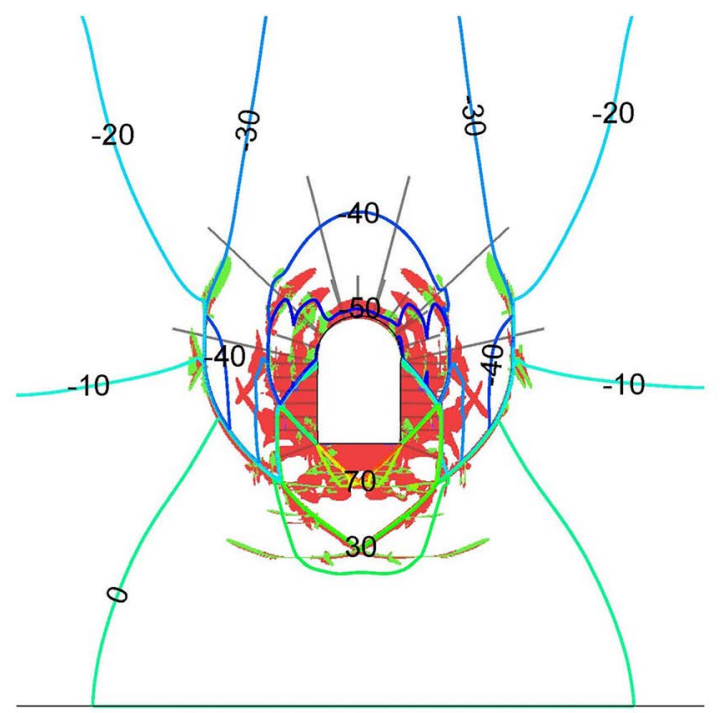

Zone
Colorby: State -Average

None
shear-n

shear-n nhear-p

shear-n shear-p tension-p
shear-p

(lear-p the

tension-n shear-p tension-p Cable
Colorby: Uniform

(e) $5 \mathrm{~m}$

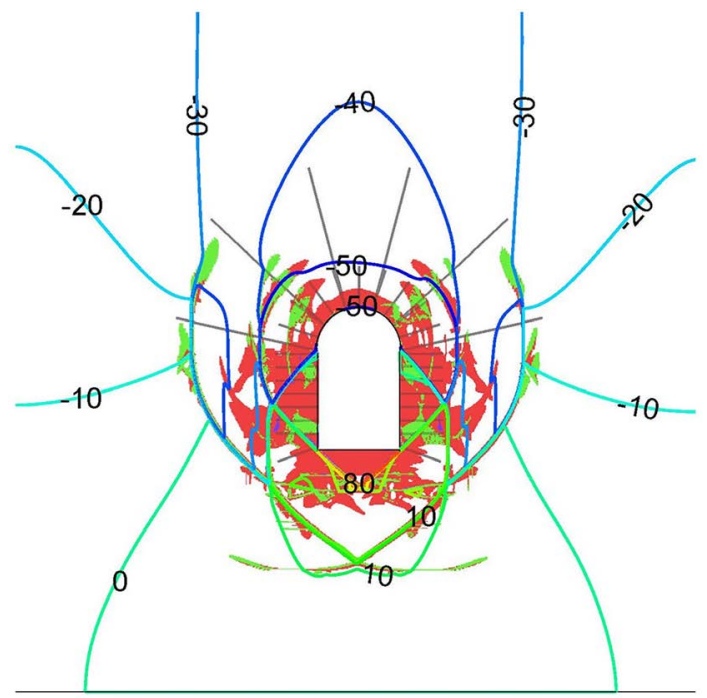

Zone
Colorby: State -Average None
shear-n

shear-n

thear-n shear-p tension-p

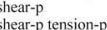

tension-n shear-p tension-p Cable
Colorby: Uniform Coloby: Uniform

(f) $6 \mathrm{~m}$ 


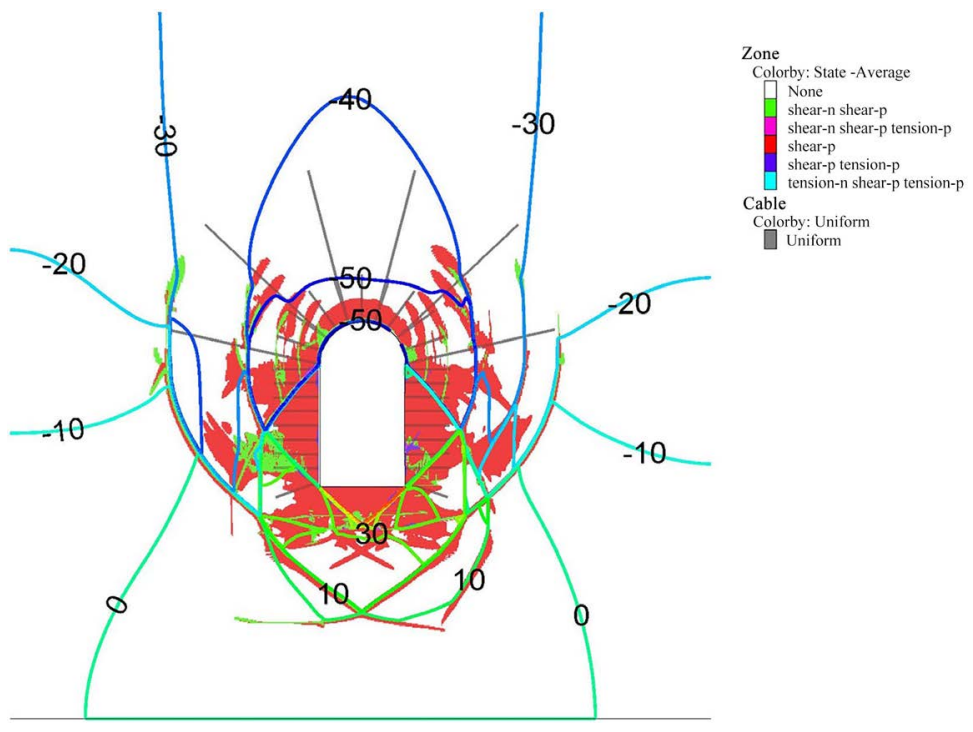

(g) $7 \mathrm{~m}$

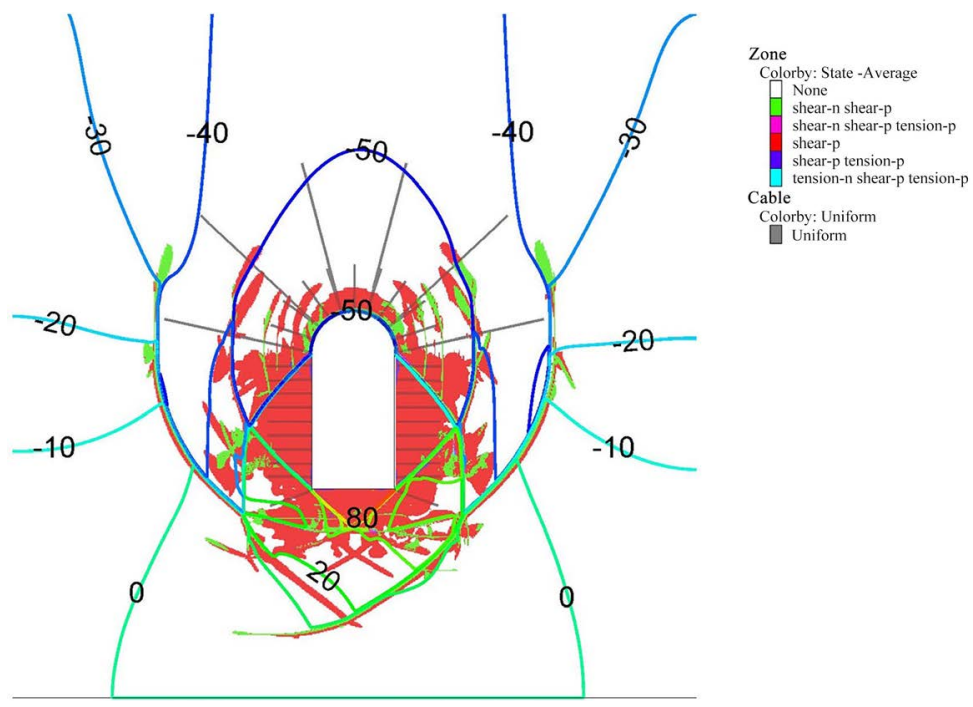

(h) $8 \mathrm{~m}$

Figure 3. Distribution and displacement isoline of fracture plastic zone in different roadway heights.

\section{Deformation Characteristics of Surrounding Rock}

Under the disturbance of excavation, the stress of surrounding rock will be redistributed, which will lead to the deformation and failure of surrounding rock, especially the continuous increase of mining depth, and the deformation and failure of surrounding rock will be aggravated. Surrounding rock is not only the main bearing body of roadway redistribution stress, but also the object of roadway stability control. Therefore, the key to maintain the stability of roadway is the strength of surrounding rock.

In Figure 4, when the roadway height is from $1 \mathrm{~m}$ to $8 \mathrm{~m}$, the surrounding rock deformation in $\mathrm{Z}$ direction forms an "inverted triangle" at the floor, and the height of the "inverted triangle" is constant no matter what the roadway height 
is, that is, the area is certain; the maximum displacement of surrounding rock moving along the positive direction of $\mathrm{Z}$ axis reaches the peak value when the roadway height is $5 \mathrm{~m}$, while the maximum displacement value of surrounding rock moving along the negative direction of $\mathrm{z}$-axis increases with the increase of roadway height.

From Figure 5, we can see that: at the depth of $2 \mathrm{~m}$, floor heave exists in the way of close to horizontal straight line, corresponding to the situation that the height of "inverted triangle" fracture zone of all cross-sections in the above figure is consistent; the path of roof subsidence is a smooth curve, that is, under the influence of disturbance, the roof is destroyed step by step, and there is no sudden collapse; the horizontal displacement track of two sides of surrounding rock is "ladder type", and severe large-scale damage occurs between 0 and $3 \mathrm{~m}$. After $3 \mathrm{~m}$, the displacement is a gentle step until the displacement of surrounding rocks is 0 after $17 \mathrm{~m}$.
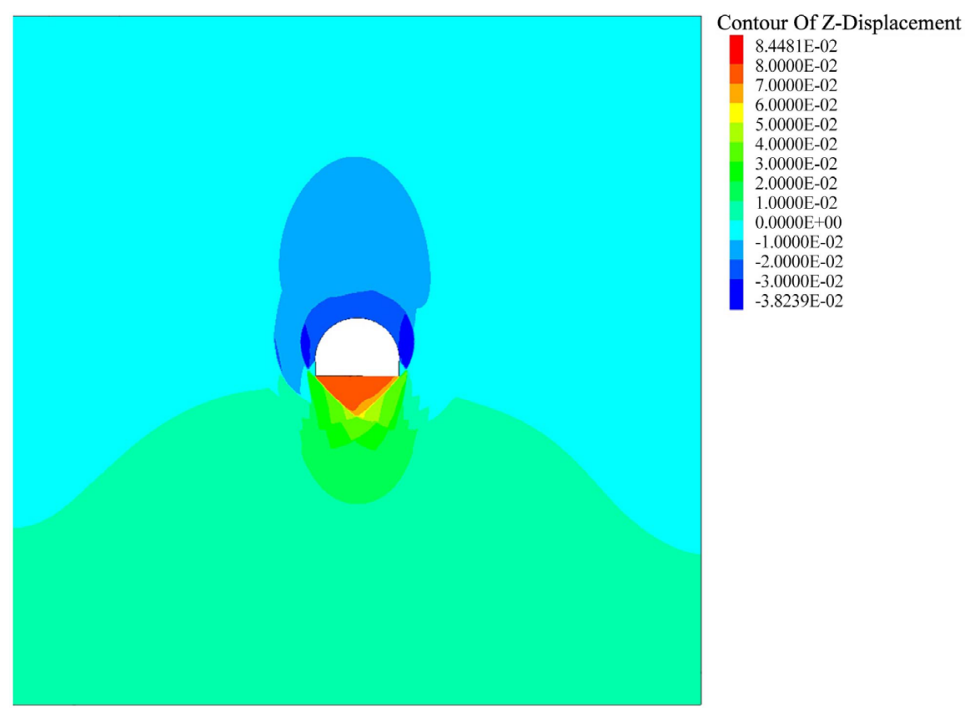

(a) $1 \mathrm{~m}$
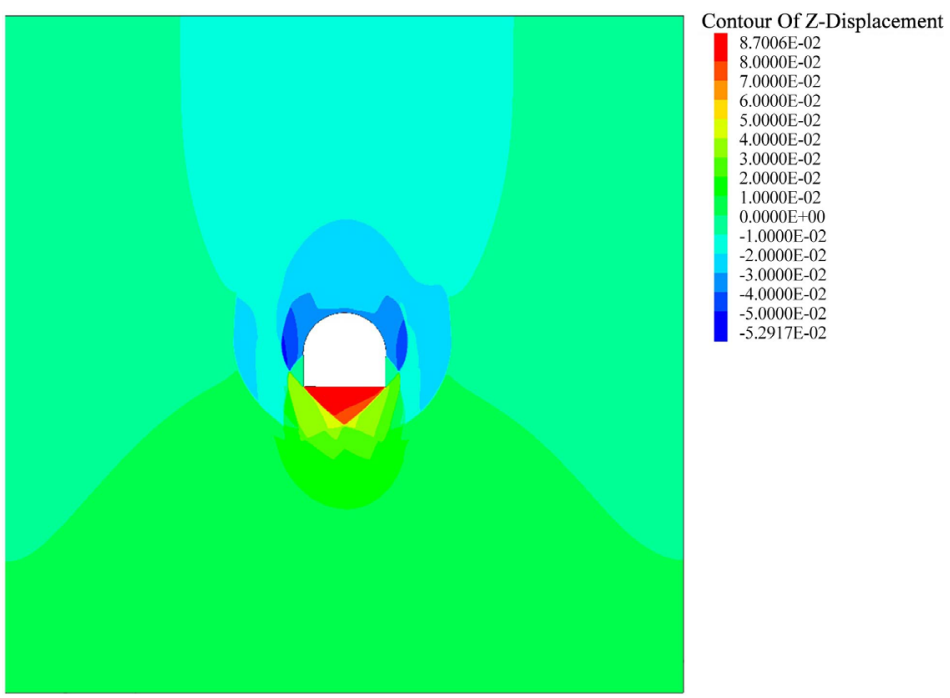

(b) $2 \mathrm{~m}$ 


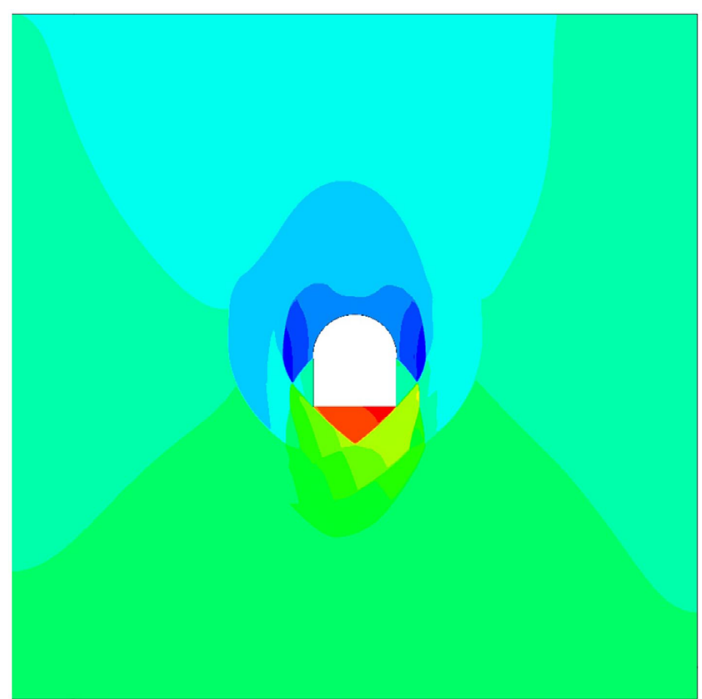

Contour Of Z-Displacement $9.5706 \mathrm{E}-02$
$9.0000 \mathrm{E}-02$

$8.0000 \mathrm{E}-02$

$7.0000 \mathrm{E}-02$

$6.0000 \mathrm{E}-02$

$5.0000 \mathrm{E}-02$

$4.0000 \mathrm{E}-02$

3.0000E-02

$2.0000 \mathrm{E}-02$
$1.0000 \mathrm{E}-02$
$0.0000 \mathrm{E}-00$

$1.0000 \mathrm{E}-02$
$0.0000 \mathrm{E}+00$

$-1.0000 \mathrm{E}-02$

$-2.0000 \mathrm{E}-02$

.0000E- 02

$4.0000 \mathrm{E}-02$

$-5.0000 \mathrm{E}-02$

$-5.7359 \mathrm{E}-02$

(c) $3 \mathrm{~m}$

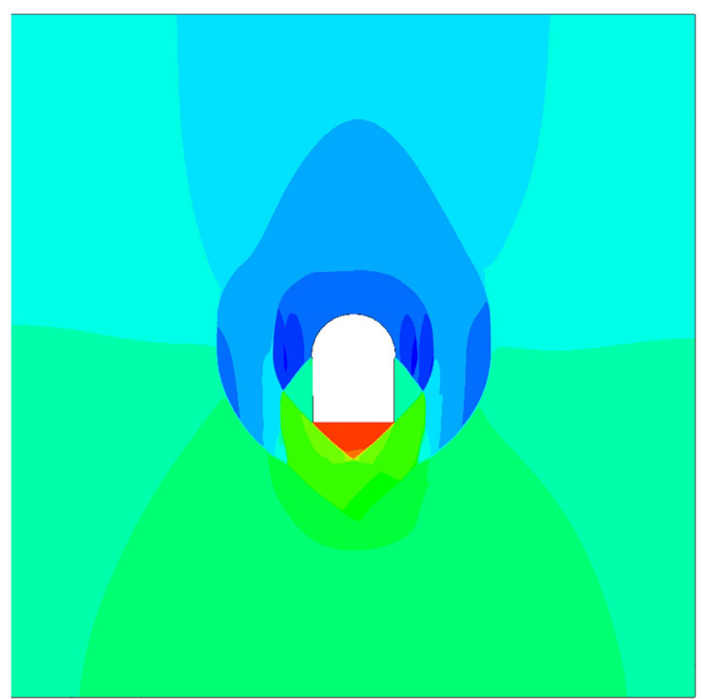

Contour Of Z-Displacement $1.1317 \mathrm{E}-01$
$1.1000 \mathrm{E}-01$

$1.10000 \mathrm{E}-0$

$9.0000 \mathrm{E}-02$

$8.0000 \mathrm{E}-02$

$7.0000 \mathrm{E}-02$

$6.0000 \mathrm{E}-02$

$5.0000 \mathrm{E}-02$

$4.0000 \mathrm{E}-02$
$3.0000 \mathrm{E}-02$

$2.0000 \mathrm{E}-02$

$1.0000 \mathrm{E}-02$

$0.0000 \mathrm{E}+00$

$1.0000 \mathrm{E}-02$

$2.0000 \mathrm{E}-02$

- $3.0000 \mathrm{E}-02$

$.0000 \mathrm{E}-02$

.

$-6.0000 \mathrm{E}-02$

(d) $4 \mathrm{~m}$

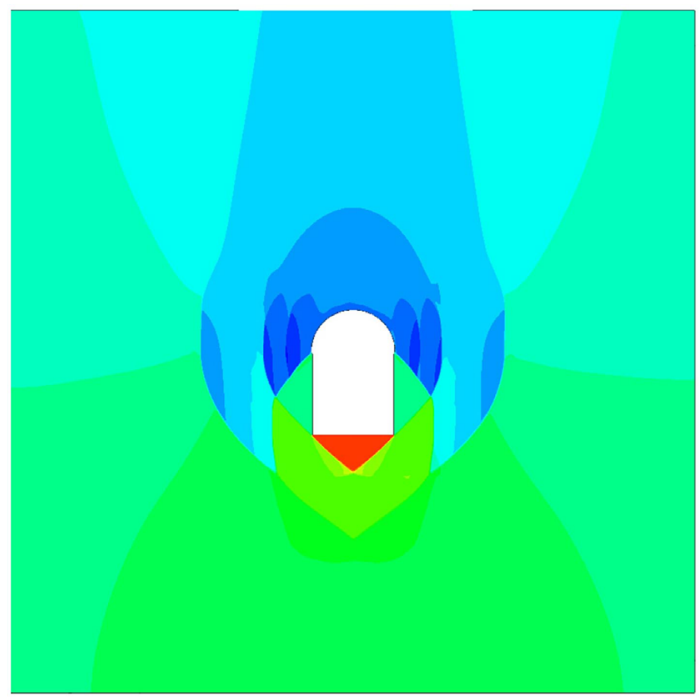

Contour Of Z-Displacement $1.1604 \mathrm{E}-01$
$1.1000 \mathrm{E}-01$

$1.0000 \mathrm{E}-01$

,0000E-02

$8.0000 \mathrm{E}-02$

$.0000 \mathrm{E}-02$

.0000E-02

.000 -02

.0000 E-02

. $0000 \mathrm{E}-02$

$1.0000 \mathrm{E}-02$

$.0000 \mathrm{E}+00$

$-1.0000 \mathrm{E}-02$

$-2.0000 \mathrm{E}-02$

$-3.0000 \mathrm{E}-02$

. $0000 \mathrm{E}-02$

.0000E- 02

$-7.0000 \mathrm{E}-02$
$-7.1183 \mathrm{E}-02$

(e) $5 \mathrm{~m}$ 

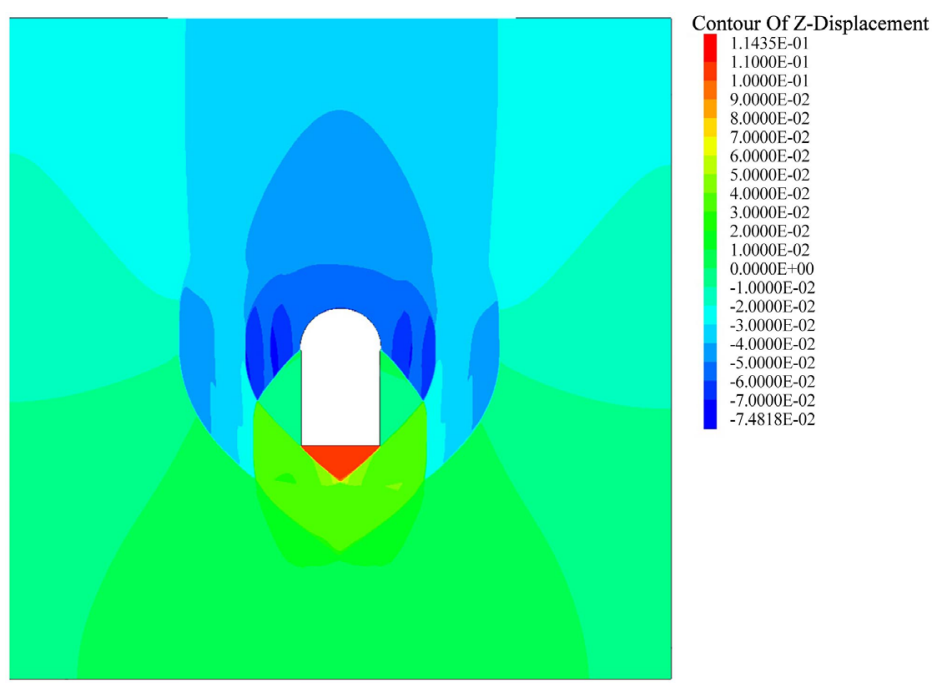

(f) $6 \mathrm{~m}$
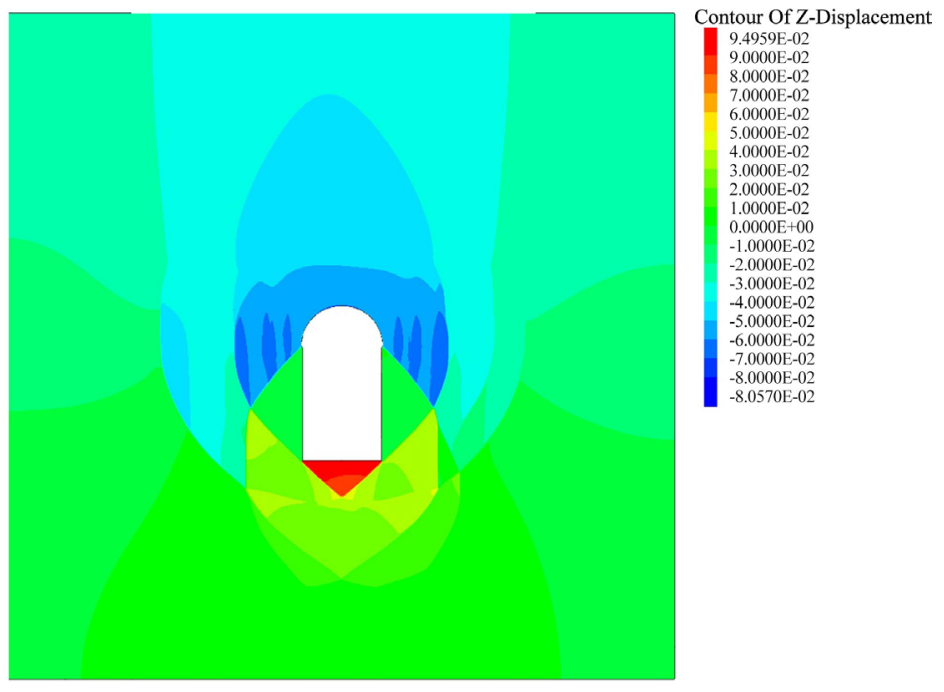

(g) $7 \mathrm{~m}$
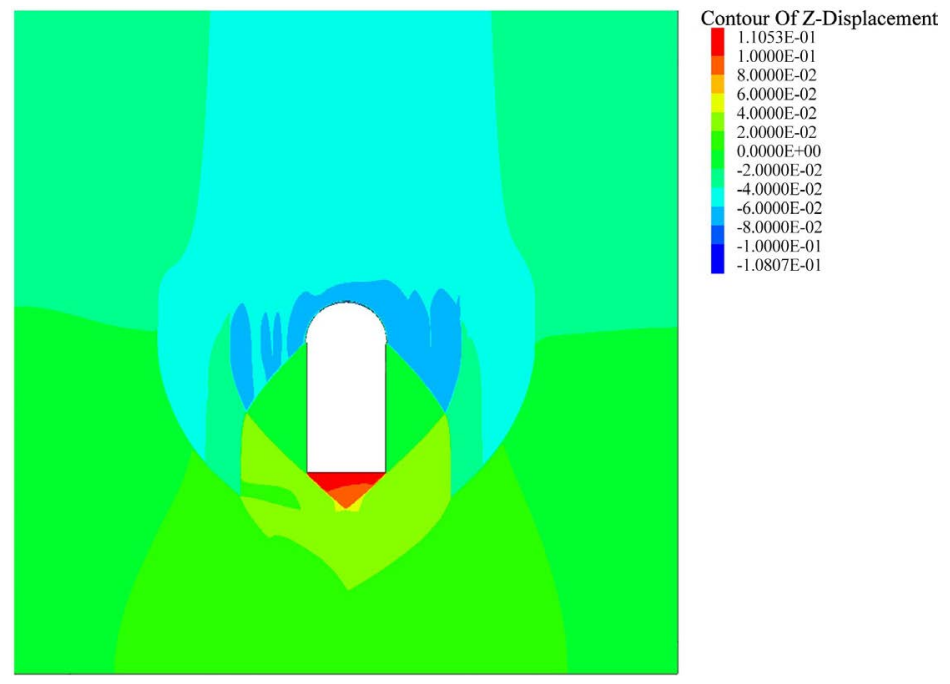

(h) $8 \mathrm{~m}$

Figure 4. Deformation characteristics of surrounding rock. 

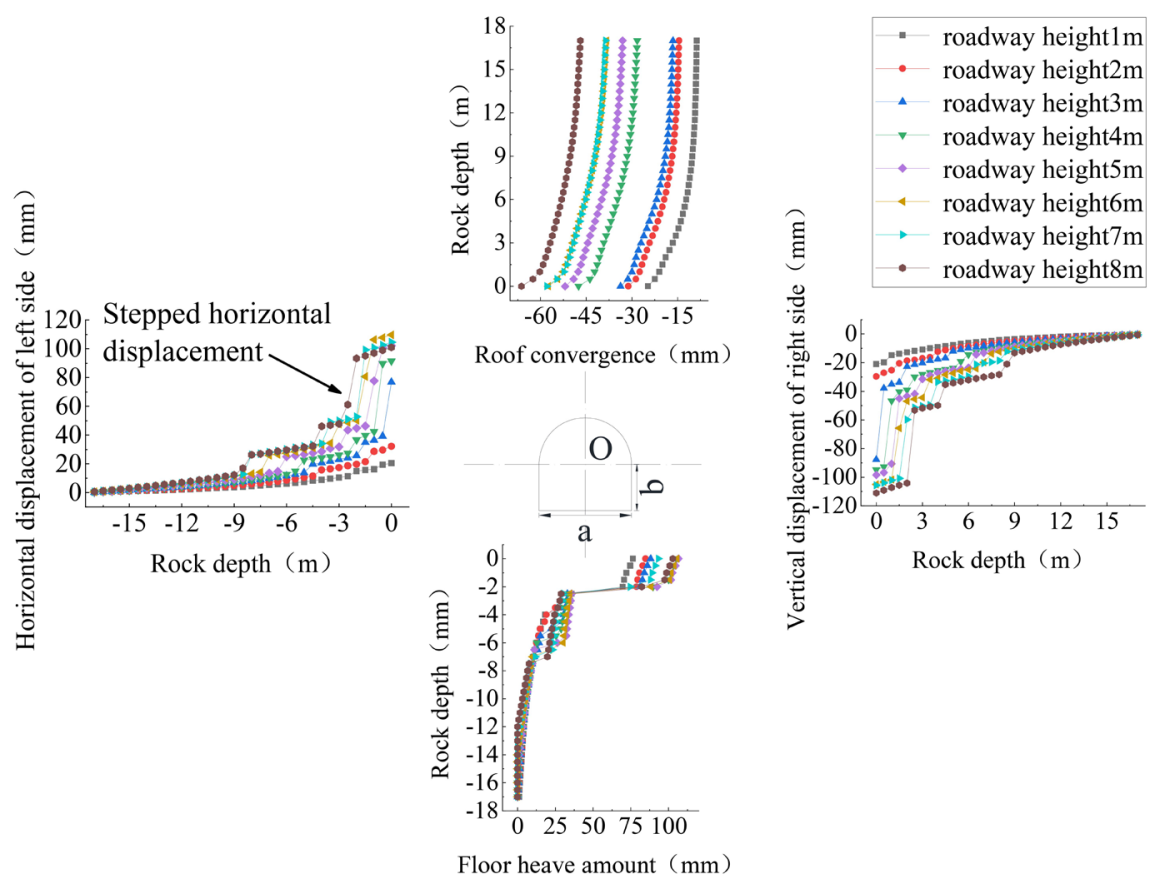

Figure 5. Displacement curve of surrounding rock.

\section{Characteristics of Support Stress Distribution of Surrounding Rock}

In coal mining, there will be bearing pressure near the coal wall of the working face. The rock mass along the direction of the working face bears most of the role of the upper fracture zone and its overlying strata. The coal rock at the front end will generate the leading bearing pressure. Affected by different strata, the location and distribution of the peak value are very important for mining. The advance bearing pressure will move forward along with the continuous advance of the working face, and stress concentration will occur at a certain position, resulting in the deformation and damage of the surrounding rock mass, resulting in water inrush, mud inrush, gas leakage, rockburst and other accidents. This section starts with the supporting pressure of the surrounding rock and simulates the influence of different roadway heights on the straight wall semicircular arch roadway.

As shown in Figure 6, when the roadway is excavated, the stress concentration occurs at the left and right sides of the arch wall of the straight wall semicircular arch roadway, and no matter what the value of the roadway height is, it mostly occurs on both sides of the arch. With the increase of the wall height, the peak values of the two sides gradually shift to the deep part of the surrounding rock, which indicates that when the wall height increases, the bearing capacity mainly depends on the deep surrounding rock. In support, the floor is not treated, so the stress of surrounding rock is mainly concentrated in the floor. In the picture, the stress in $\mathrm{z}$-axis direction of surrounding rock is mainly compressive stress. 
Cable Stress ColorScale of ZZ-Stress

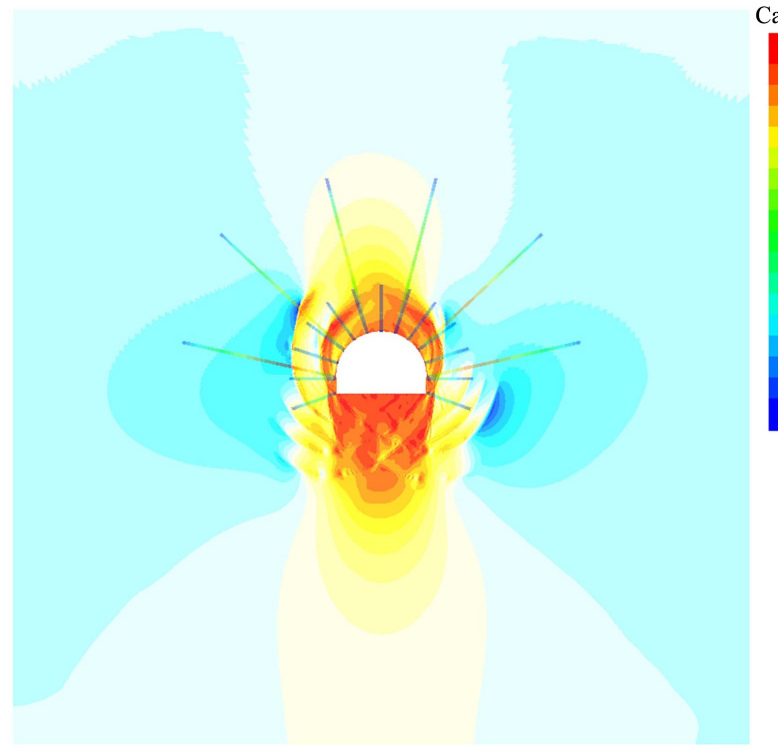

$1.6481 \mathrm{E}+07$
$1.6000 \mathrm{E}+07$

$1.5000 \mathrm{E}+07$

$1.4000 \mathrm{E}+07$

$1.3000 \mathrm{E}+07$

$1.2000 \mathrm{E}+07$

$1.1000 \mathrm{E}+07$

$1.0000 \mathrm{E}+07$

.000 E 06

$7.0000 \mathrm{E}+06$

$6.0000 \mathrm{E}+06$

$5.0000 \mathrm{E}+06$

$4.0000 \mathrm{E}+06$

$3.0000 \mathrm{E}+06$

$2.0000 \mathrm{E}+06$

$1.0000 \mathrm{E}+06$

$0.0000 \mathrm{E}+00$

$5.5330 \mathrm{E}+04$

$1.7365 \mathrm{E}+06$
$0.0000 \mathrm{E}+00$

$-2.5000 \mathrm{E}+06$

$-5.0000 \mathrm{E}+06$

$-7.5000 \mathrm{E}+06$

$-1.0000 \mathrm{E}+07$
$-1.2500 \mathrm{E}+07$

$-1.2500 \mathrm{E}+07$

$-1.5000 \mathrm{E}+07$
$-1.7500 \mathrm{E}+07$

$-1.7500 \mathrm{E}+07$
$-2.0000 \mathrm{E}+07$

$-2.2500 \mathrm{E}+07$

$-2.5000 \mathrm{E}+07$

$-2.7500 \mathrm{E}+07$

$-3.0000 \mathrm{E}+07$

$-3.2500 \mathrm{E}+07$

$-3.5000 \mathrm{E}+07$

$-3.7500 \mathrm{E}+07$

$-4.0000 \mathrm{E}+07$

$-4.2500 \mathrm{E}+07$

$-4.5000 \mathrm{E}+07$

$-4.6848 \mathrm{E}+07$

(a) $1 \mathrm{~m}$

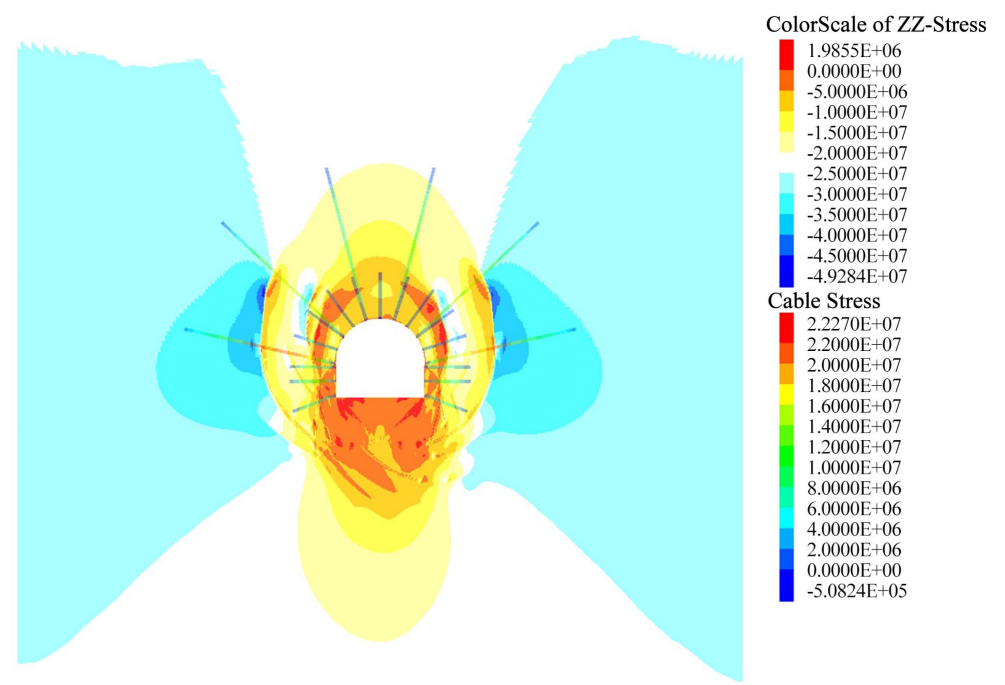

(b) $2 \mathrm{~m}$

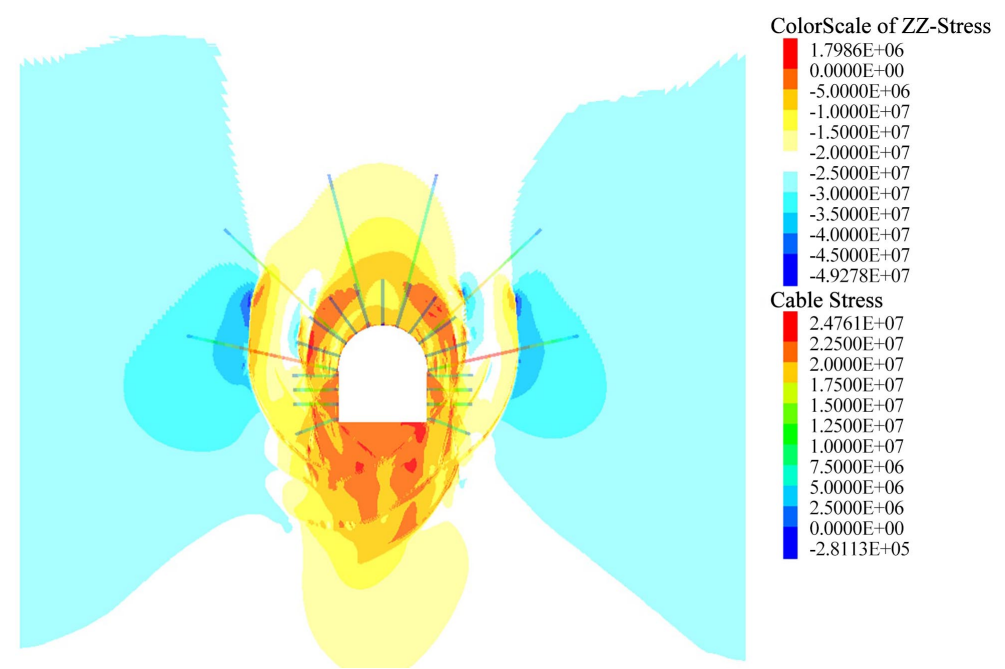

(c) $3 \mathrm{~m}$ 


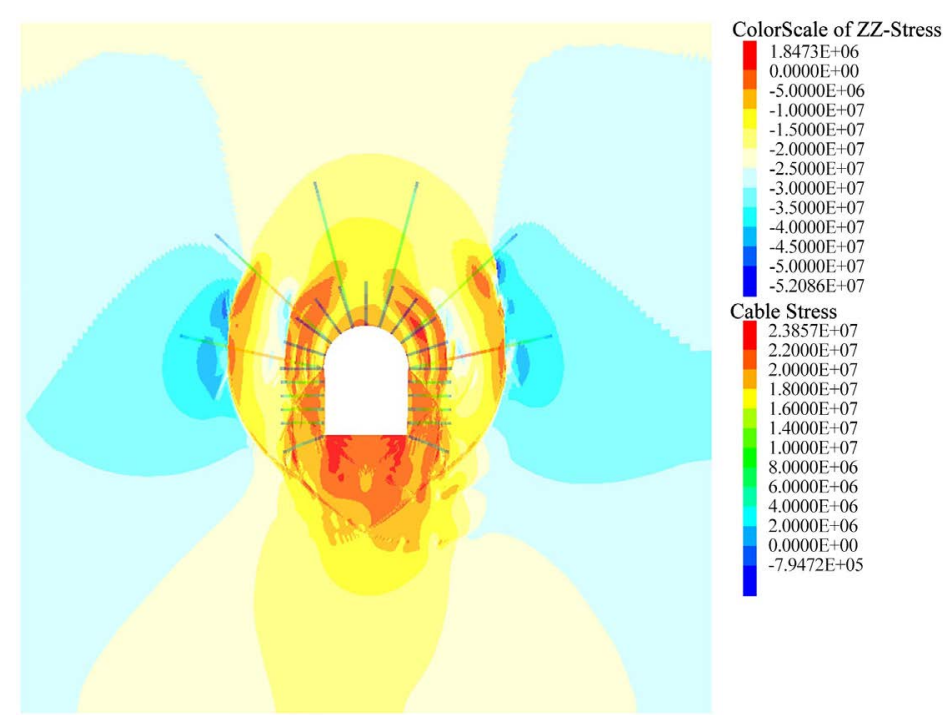

(d) $4 \mathrm{~m}$

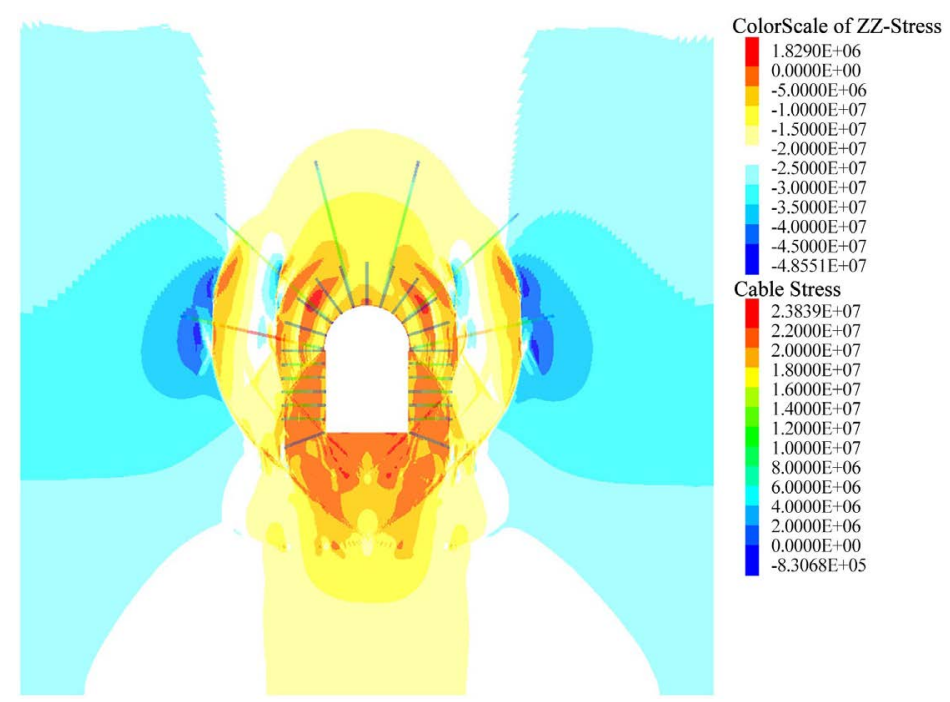

(e) $5 \mathrm{~m}$

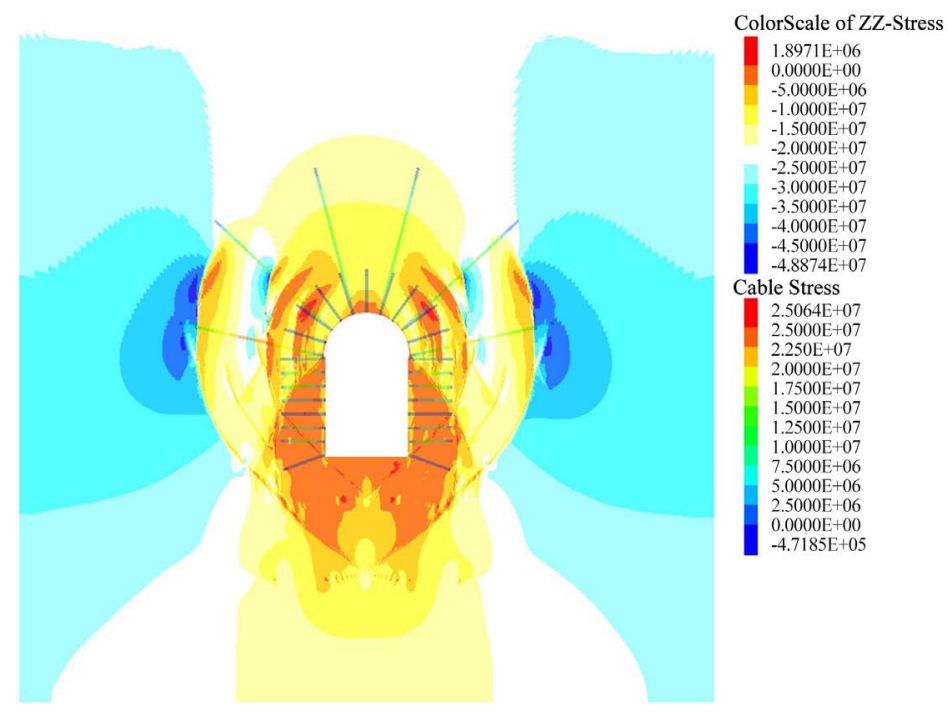

(f) $6 \mathrm{~m}$ 


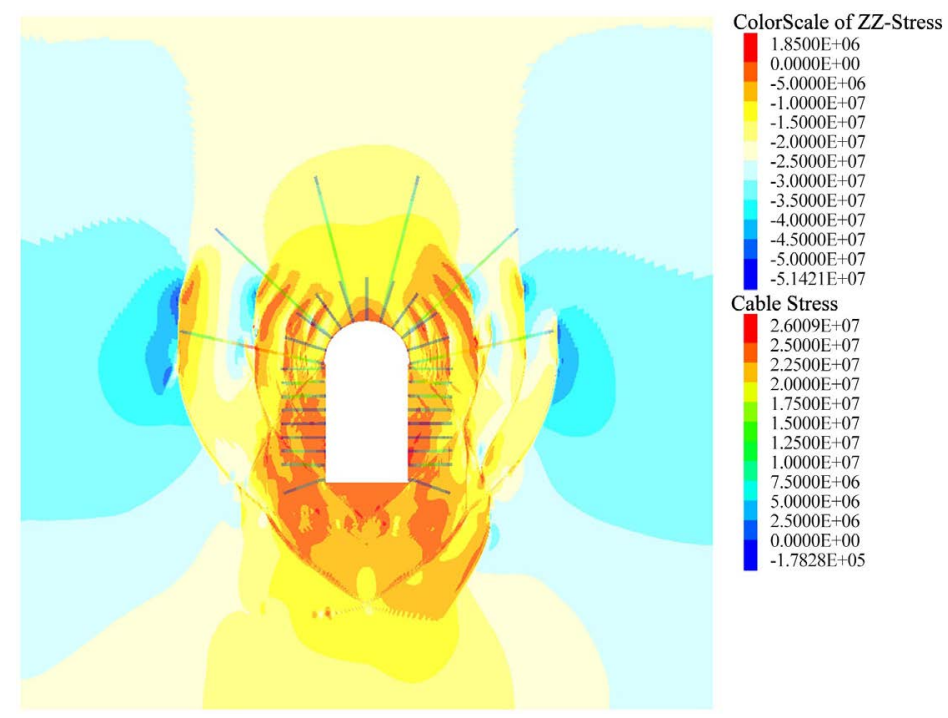

(g) $7 \mathrm{~m}$

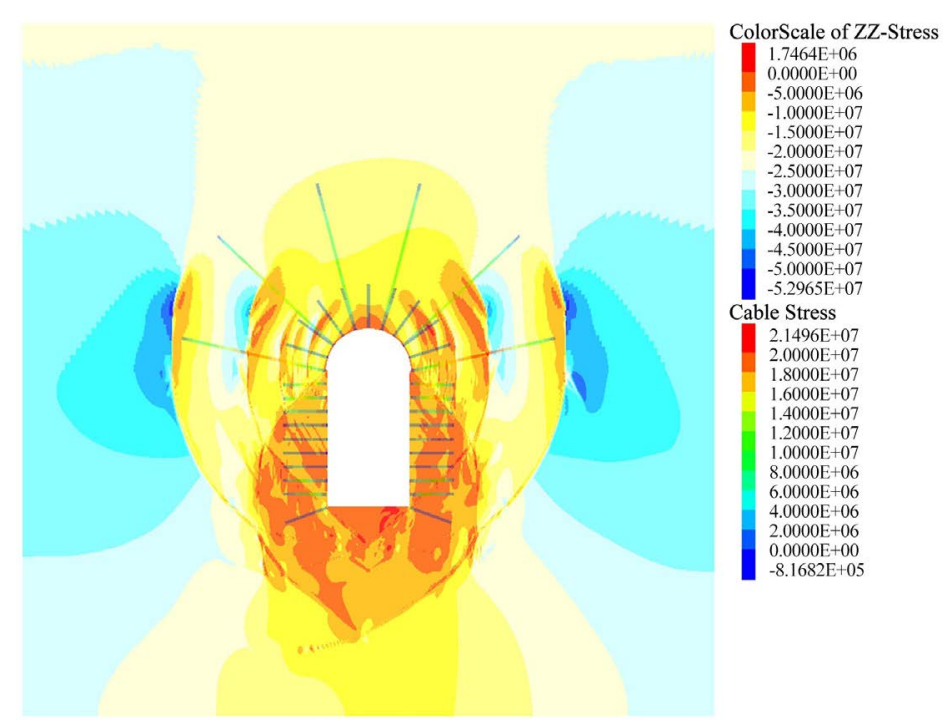

(h) $8 \mathrm{~m}$

Figure 6 Characteristic diagram of support stress distribution

The strata between different levels are relatively complete, and the abutment pressure is also concentrated in these relatively complete blocks. Therefore, the characteristics of "zonal concentration" of stress in strata between multiple fracture zones are formed.

With the increase of roadway height, the relative state of zonal fracture of surrounding rock has not been changed. It is still the inherent zonal fracture form of straight wall semi-circular arch roadway. Its bearing pressure range is wide, and the characteristics of "zonal concentration" between fracture zones have not changed.

\section{Engineering Example}

The shanghaimiao mining area in Inner Mongolia is located about $63 \mathrm{~km}$ away 
from otokeqian banner, Ordos City, southwest of Inner Mongolia Autonomous Region. It is located in the western edge of Ordos fault block. Regional folds and faults are developed, mainly fault structures. There is no magmatic rock on the surface and borehole, and the stratum dip angle is gentle.

Taking the 114 return air roadway of No. 1 Coal Mine in new Shanghai as an example, the opening position of 114 return air roadway is along the third fork of 15 coal return air connecting lane, and the excavation is conducted at a slope of $3 \%$. The roadway is located in the Jurassic Yan'an formation, and the lithology of the roadway is mainly sandy mudstone, and the geological structure is relatively simple.

The initial support method is as follows: the design net width of the roadway is $4000 \mathrm{~mm}$, the net height is $3800 \mathrm{~mm}$, the section shape is straight wall semicircle arch, and the support mode is "bolt mesh cable spray $+36 \mathrm{U}$ steel". The first support adopts bolt mesh shotcreting, ordinary screw thread steel bolt with diameter of $20 \times 2100 \mathrm{~mm}, \mathrm{k} 2370$ resin cartridge lengthening anchoring, spacing between rows of $800 \times 800 \mathrm{~mm}$, steel mesh of diameter of $6.5 \mathrm{~mm}$, mesh size of $100 \times 100 \mathrm{~mm}$, spraying thickness of $50 \mathrm{~mm}$, and secondary spraying thickness of $150 \mathrm{~mm}$ after erection of $36 \mathrm{U}$ section steel.

After the completion of roadway support, there are different types of failure characteristics, mainly manifested as floor bulging, spray layer falling off, shed leg twisting, etc.: Figure 7.

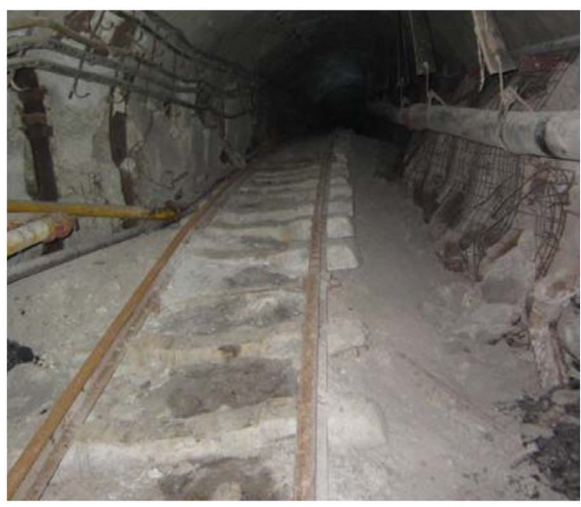

(a) Floor fracture and bulged

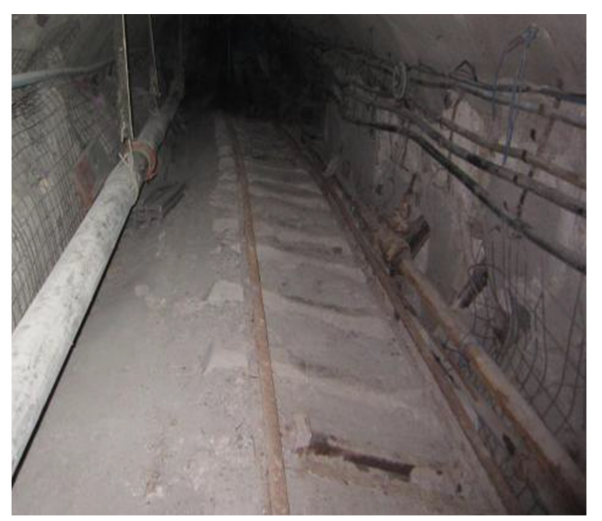

(b) Floor bulging 


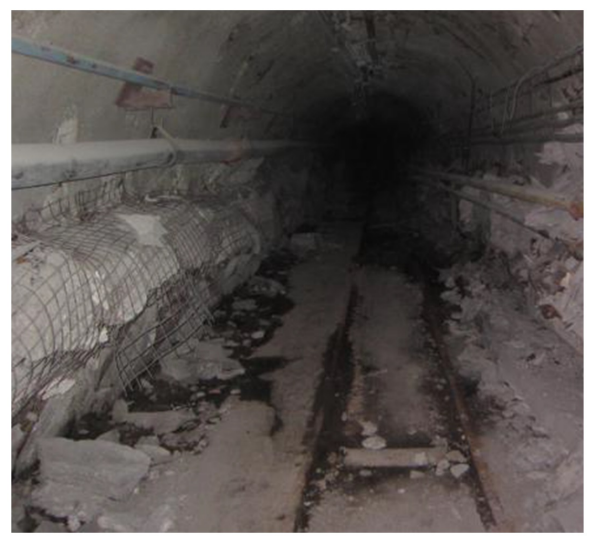

(c) The bottom of the wall is broken

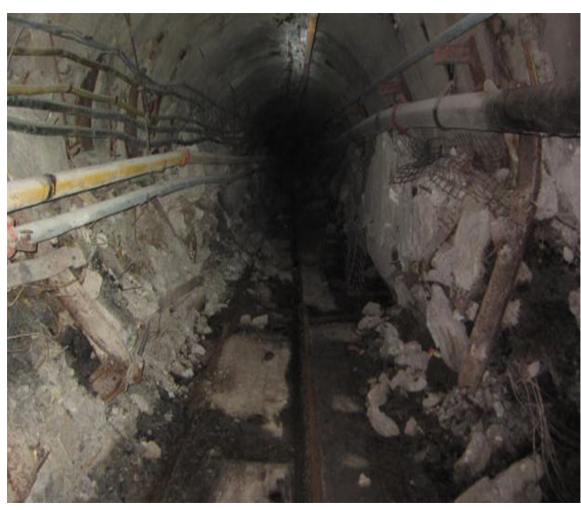

(d) The shed legs are twisted and squeezed in the spray layer falls off

Figure 7. Deformation and failure of return air roadway in 114 mining area.

From the deformation characteristics of surrounding rock in Figure 4, it can be seen that the main fracture zone of straight wall semicircular arch roadway does not only exist in the roof and two sides, but also the floor surrounding rock has "inverted triangle" damage, which will cause floor bulging. Therefore, the surrounding rock of floor should be treated at the same time. According to the distribution characteristics of surrounding rock bearing pressure, two anchor cables are symmetrically arranged at the stress concentration at the left and right ends of the arch wall; the surrounding rock of the two sides will move to the bottom plate due to the stress extrusion, and anchor cables are laid at both ends of the bottom plate. The specification of the anchor cable is $\varphi 17.8 \times 7000 \mathrm{~mm}$ ordinary steel strand anchor cable. Five pieces of msk2550 anchoring agent are used for each cable. The pre tightening force is $120 \mathrm{kn}$, the exposed length is 150 - $250 \mathrm{~mm}$, and the row spacing is $1400 \times 2100 \mathrm{~mm}$.

"Anchor net (cable) + steel ladder shotcreting support + reverse arch anchor mesh shotcreting" support is adopted. The thickness of initial spraying shall not be less than $50 \mathrm{~mm}$, and the grade of shotcrete shall be C20. After the initial shotcreting, one support is carried out, and the shotcrete is $50 \mathrm{~mm}$ after the primary support. Then the secondary support is carried out, and the secondary support of "bolt mesh shotcreting" is adopted for the top slope, and the row spacing between the bolts is $700 \times 800 \mathrm{~mm}$. After the second support, the shot- 
crete is $50 \mathrm{~mm}$, and the secondary support bolt and the first support bolt are arranged in five patterns. The design anchoring force of anchor rod is $80 \mathrm{KN}$ and the torque is $300 \mathrm{~N} \cdot \mathrm{M}$. The top and bottom anchor bolts are made of high-strength bolts of $20 \times 2800 \mathrm{~mm}$, and each bolt uses $3 \mathrm{msk} 2550$ anchoring agent. The inverted arch anchor bolt is made of $\varphi 20 \times 2400 \mathrm{~mm}$ high-strength bolt, and the anchoring agent is required to be combined with cement slurry for full-length anchoring.

\section{Conclusions}

This paper simulates the surrounding rock plastic zone, surrounding rock deformation characteristics and surrounding rock supporting pressure distribution of the straight wall semicircular arch roadway under different roadway height values. The specific conclusions include the following aspects:

1) The fracture zone at the floor of the straight wall semi-circular arch roadway develops layer by layer in the form of " $X$ " and the displacement contour at the roof is "eggshell shaped".

2) The z-direction surrounding rock deformation of straight wall semicircular arch roadway exists in the form of "inverted triangle" at the bottom plate, and the height of "inverted triangle" is constant no matter what the value of roadway height is, that is, the area is certain.

3) When the roadway is excavated, the stress concentration occurs at the left and right sides of the arch wall of the straight wall semicircular arch roadway, and no matter what the value of the roadway height is, it mostly occurs on both sides of the arch.

4) When the simulation results are combined with the specific engineering, the support guidance is carried out according to the partition fracture mode of the straight wall semi-circular arch, such as driving anchor cable at the stress concentration.

\section{Funding Information}

The Fundamental Research Funds for the Universities of Henan Province", Number: NSFRF170923;

Department of Science and Technology Guidance Project (Henan Science and Technology Research Plan, Social Development Field), Number: 172102310705;

Henan Provincial Key Laboratory of Underground Engineering and Disaster Prevention and Control (Henan University of Technology) independent project funding.

\section{Conflicts of Interest}

The authors declare no conflicts of interest regarding the publication of this paper.

\section{References}

[1] Adams, G.R. and Jager, A.J. (1980) Petroscopic Observation of Rock Fracturing 
Ahead of Stope Faces in Deep-Level Gold Mines. Journal South African Institute of Mining \& Metallurgy, 80, 204-209. https://doi.org/10.1016/0148-9062(80)90623-3

[2] Shemyakin, E.I., Fisenko, G.L., Kurlenya, M.V., Oparin, V.N., Reva, V.N., Glushikhin, F.P., Rozenbaum, M.A., Tropp, É.A. and Kuznetsov, Y.S. (1986) Zonal Disintegration of Rocks around Underground Workings, Part 1: Data of in Situ Observations. Soviet Mining, 22, 157-168. https://doi.org/10.1007/BF02500863

[3] He, Y.N. (1991) Analysis of Loose Zone around the Roadway in Soft Rock. Journal of China Coal Society, 2, 63-70. https://doi.org/10.13225/j.cnki.jccs.1991.02.009

[4] Odintsev, V.N. (1994) Mechanism of the Zonal Disintegration of a Rock Mass in the Vicinity of Deep-Level Workings. Journal of Mining Science, 30, 334-343. https://doi.org/10.1007/BF02048178

[5] Reva, V.N. (2002) Stability Criteria of Underground Workings under Zonal Disintegration of Rocks. Journal of Mining Science, 38, 31-34. https://doi.org/10.1023/A:1020236617544

[6] Guzev, M.A. and Paroshin, A.A. (2001) Non-Euclidean Model of the Zonal Disintegration of Rocks around an Underground Working. Journal of Applied Mechanics and Technical Physics, 42, 131-139. https://doi.org/10.1023/A:1018877015940

[7] Qian, Q.H., Zhou, X.P. and Xia, E. (2012) Effects of the Axial in Situ Stresses on the Zonal Disintegration Phenomenon in the Surrounding Rock Masses around a Deep Circular Tunnel. Journal of Mining Science, 48, 276-285 https://doi.org/10.1134/S1062739148020086

[8] Qian, Q.H. and Zhou, X.P. (2011) Non-Euclidean Continuum Model of the Zonal Disintegration of Surrounding Rocks around a Deep Circular Tunnel in a Non-Hydrostatic Pressure State. Journal of Mining Science, 47, Article Number: 37. https://doi.org/10.1134/S1062739147010059 